\title{
Performance Comparison of Routing protocols Using Different Mobility Models
}

\author{
Shailender Gupta \\ Department of Electronics Engineering, YMCA UST, Faridabad, India \\ Email: shailender81@gmail.com \\ Chirag Kumar \\ Department of Electronics Engineering, YMCA UST, Faridabad, India \\ Email: chiragarora35@gmail.com \\ Seema Rani \\ Department of Electronics and Communication Engineering, BSAITM, Faridabad, India \\ Email: yadav.rani@gmail.com \\ Bharat Bhushan \\ Department of Electronics Engineering, YMCA UST, Faridabad, India \\ Email: bhrts@yahoomail.com
}

\begin{abstract}
Communication in Mobile Ad Hoc Network (MANET) is accomplished using routing protocols. These protocols provide an efficient and reliable path for data sharing. In static environment where the nodes are stationary these protocols performs exceptionally well but in an environment having mobile nodes the performance of these protocols degrade drastically. To investigate this factor various researchers developed mobility models using simulation tools such as QUALNET, NS-2 etc. These models represent the erratic movement of nodes and give us an idea regarding their location, velocity and acceleration change over time. This paper is an effort to study the effect of mobility models such as Random Way Point, File and Group Mobility Models on the performance of routing protocols using QUALNET simulator. The results show that the choice of mobility models affect the performance of routing protocol significantly.
\end{abstract}

Index Terms - Mobility, Routing protocols, Mobility Models

\section{INTRODUCTION}

MANET [1-4] is a collection of mobile wireless nodes that does not require any fixed infrastructure like base station or centralized authority for its operation. The nodes in MANET have [5-6] low bandwidth, limited processing capability and battery power. Moreover the nodes move randomly and continuously, which results in variation of topology. Keeping in view these limitations different researchers have developed routing protocols for information sharing. The various routing protocols [7-8] can be classified as follows:

- Table Driven Routing protocol: These protocols maintain consistent and up to date information about the network topology by flooding Hello Request and
Reply packets. A node which requires a route to a distant node checks its routing table and sends the data packets accordingly. These protocols have large bandwidth, memory requirements making them more suitable for wired networks.

- On Demand Routing protocols: The protocol creates route only when it is required i.e. when a node needs a route to a distant node it floods route request packet to its neighboring node. The process of flooding goes on at each and every node till the route request packet reaches at the destination node. These types of protocols are more suitable for ad hoc network as they do not have large memory and bandwidth. In comparison to Table Driven routing protocols the routing delay is quite high since the routes are created when required

- Hybrid routing protocols: The protocols try to combine the merits of both the routing strategies i.e. Table Driven and On Demand scheme. In this routing strategy the network is divided into small clusters. The routing scheme used within the cluster is Table Driven while outside the cluster it is On Demand.

All the routing protocols perform well when the nodes are stationary but in an environment having mobile nodes the performance may degrades significantly. The mobility also affects the stability of the network as higher is the mobility more will be the connection failures resulting in lower throughput and packet delivery ratio. To incorporate the effect of mobility, researchers have provided various mobility models [9-18]. The mobility models lower the randomness of the mobile nodes by giving an idea regarding their location, velocity and acceleration change over time. Various mobility models have been proposed in literature and they affect the performance of routing protocol differently. This paper compares the performance of various routing protocols at application 
layer under the effect of mobility by means of various mobility models such as Random Way point, file and group mobility model.

The paper has been organized as follows: Section 2 gives the brief introduction to mobility models used in simulation process. In section 3 the simulation process is explained. Section 4 describes the impact of mobility on various routing protocols. Section 5 provides the conclusion followed by references.

\section{INTRODUCTION TO MOBILITY MODELS}

Various mobility models used in the simulation process are Random Way Point (RWP), File and Group Mobility Model.

Random Way Point Mobility Model (RWP): In this Mobility model, the nodes of the network select random locations as their destinations and start moving towards these destinations by selecting velocity from the predefined range $\left[0, \mathrm{~V}_{\max }\right]$ and keep on moving. As the node reaches its destination, it waits for some time known as pause time and selects new destination. It repeats the above process as the pause time is over and keeps on repeating the whole procedure until the simulation ends as shown in Figure. 1.

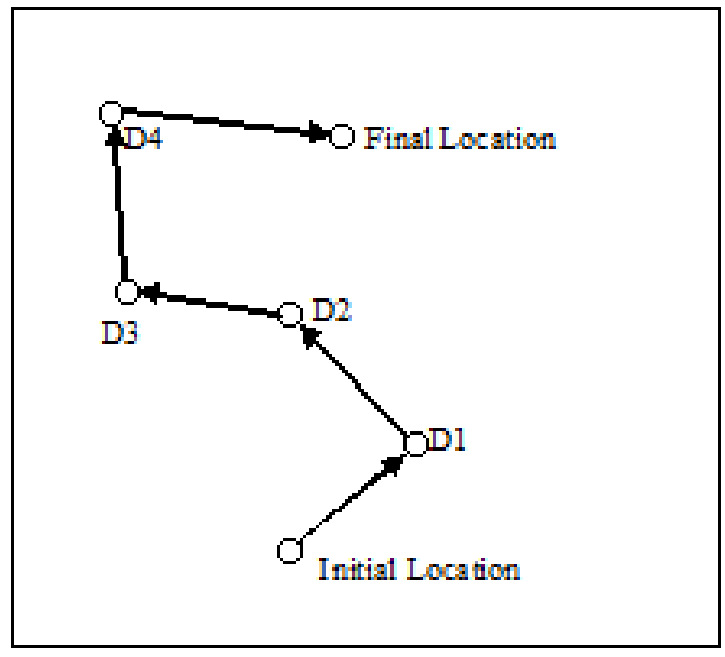

Figure. 1 Random Way Point Mobility Model

Group Mobility Model(GM): In this model the nodes move in the groups. The motion of the group is defined by the leader of the node and movement of individual node is defined by any one of the entity mobility models as Random Way Point, Random Walk and Random Direction. The QUALNET uses the random way point mobility model for the group movement as well as for the individual node movement as shown in Figure. 2.

File Mobility: The nodes move according to a file specifying node movement at different simulation times. The file contains waypoints for each node specifying node's next position, time at which the node arrives at the location and orientation (optionally). The node moves from one position to the next in a straight line at a constant speed as shown in Figure. 3.

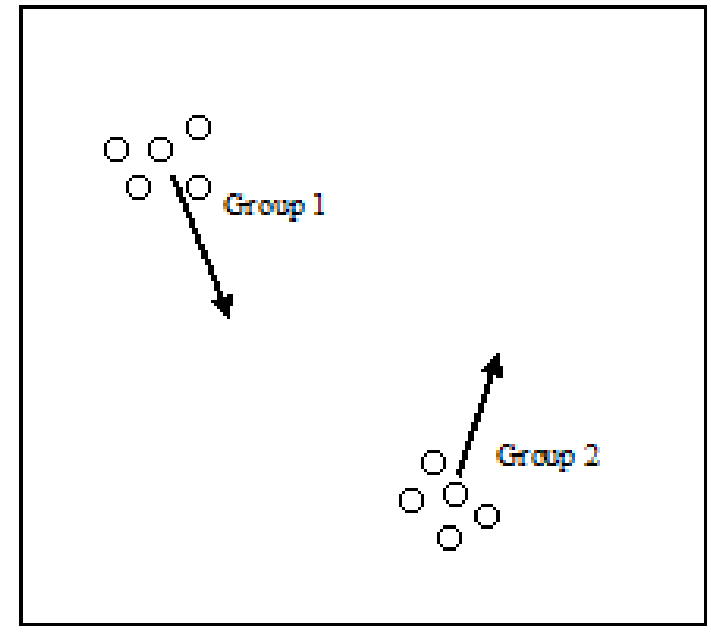

Figure. 2 Group Mobility Model

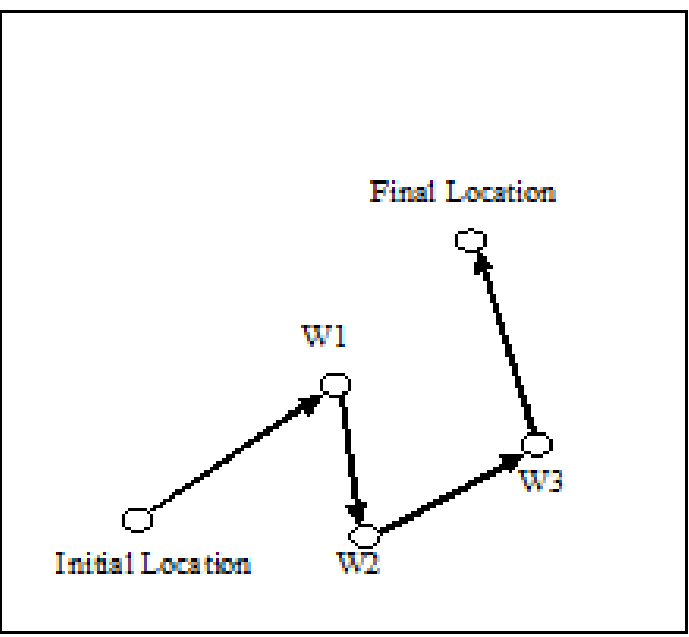

Figure. 3 File Mobility model

\section{Simulation SETUP}

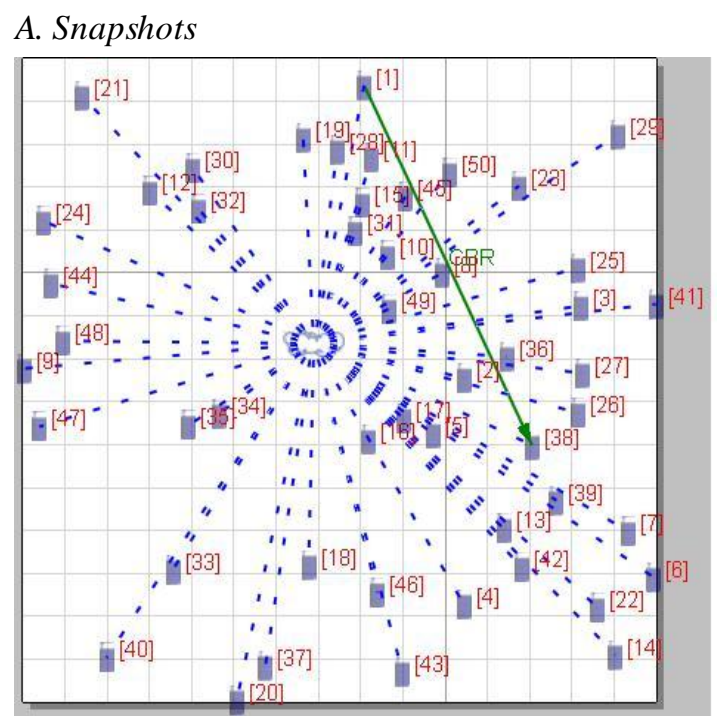

Figure. 4 Snapshot

Figure. 4 shows the snapshot of the simulation process carried out in QUALNET simulator. 


\section{B. Simulation Tool Used}

The simulation Process is carried out on QUALNET. The reason for the using the QUALNET is its speed, scalability, accuracy and portability. The speed of simulation enables fast results but more importantly enables real-time network simulation, which supports hardware, software, and human-in-the-loop simulation.

\section{Simulation Setup Parameter}

Table I shows the various parameters used in the simulation process.

TABLE I. SiMULATION SETUP PARAMETERS

\begin{tabular}{|c|c|}
\hline Parameter & Description \\
\hline $\begin{array}{c}\text { Size of } \\
\text { Region }\end{array}$ & Squo*1500 Sq. Units \\
\hline $\begin{array}{c}\text { Shape of } \\
\text { Region }\end{array}$ & File Mobility Model \\
Mobility \\
Model Used \\
Random Way Point(RWP) \\
Group Mobility Model(GM)
\end{tabular}

\section{Performance Metric Used}

Various performance metric used for the simulation process are as follows:

Average End-to-End Delay: Defined as the time taken by a packet to travel across a network from source to destination node and it includes all possible delays caused during route discovery, retransmission delays at the MAC layer, propagation and transfer times.

Throughput: Defined as the average rate of successful message delivered over a communication channel.

Average Jitter: Defined as the standard deviation from true periodicity of an assumed periodic signal in electronics and telecommunications, often in relation to a reference clock source.

Packet Delivery Ratio: Defined as the Ratio of Total Packet Received to the Total Packet Send. If Packet Delivery Ratio is high then it shows that it can receive maximum packet.

\section{RESULTS AND DISCUSSIONS}

\section{A. Impact on On Demand Routing protocols}

Average End to End Delay: Figure. 5 shows the performance of various On Demand routing protocols in terms of average end to end delay under the effect of mobility. Following inferences can be made:

- Location Aided Routing (LAR) routing protocol is having highest value of end to end delay followed by Ad-hoc On demand Distance Vector routing (AODV) and Dynamic Source Routing (DSR) routing protocols in each of the mobility models (RWP, File and Group).

- LAR is having highest value and DSR is having least value of end to end delay in case of Random Way Point Mobility Model.

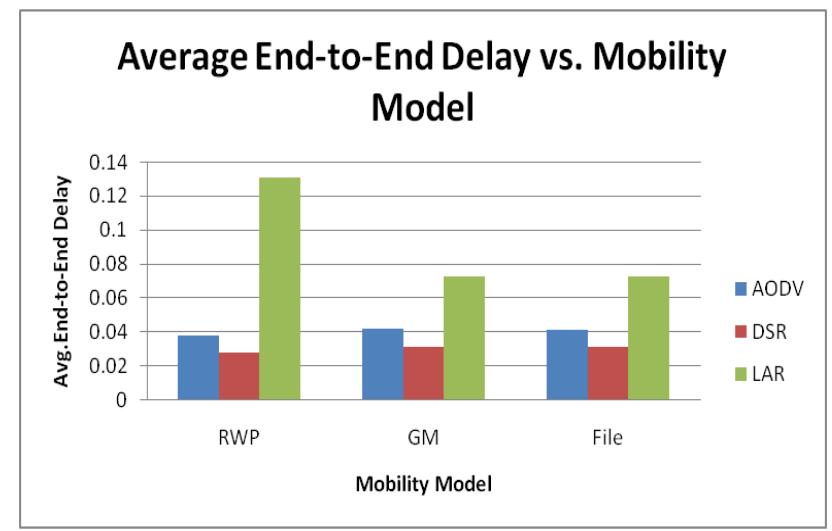

Figure. 5 Average End to End Delay Vs Mobility Model

Throughput: Figure. 6 shows the performance of various routing protocols in terms of throughput under the effect of mobility. Following inferences can be made:

- In case of RWP mobility model, the value of throughput is highest for LAR routing protocol followed by DSR and AODV.

- In case of Group Mobility and file mobility models, DSR protocol is having highest value of throughput followed by LAR and AODV.

- AODV has least value of throughput for all the mobility models (RWP, GM, and File)

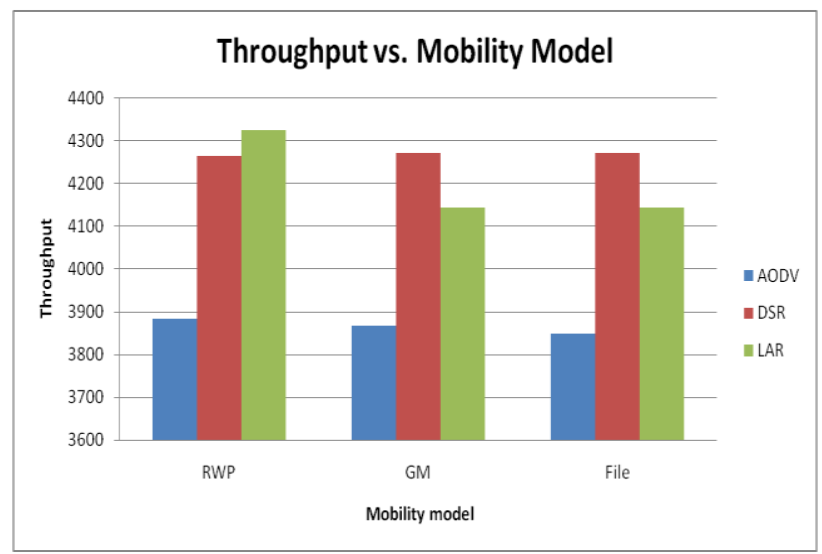

Figure. 6 Throughput Vs Mobility Model 
Average Jitter: Figure. 7 shows the performance of various routing protocols in terms of Average Jitter under the effect of mobility. Following inferences can be made:

- The value of average jitter is highest for AODV routing protocol followed by LAR and DSR in case of RWP mobility Model,.

- DSR is having least value among all the three routing protocols for Random way point mobility model (RWP).

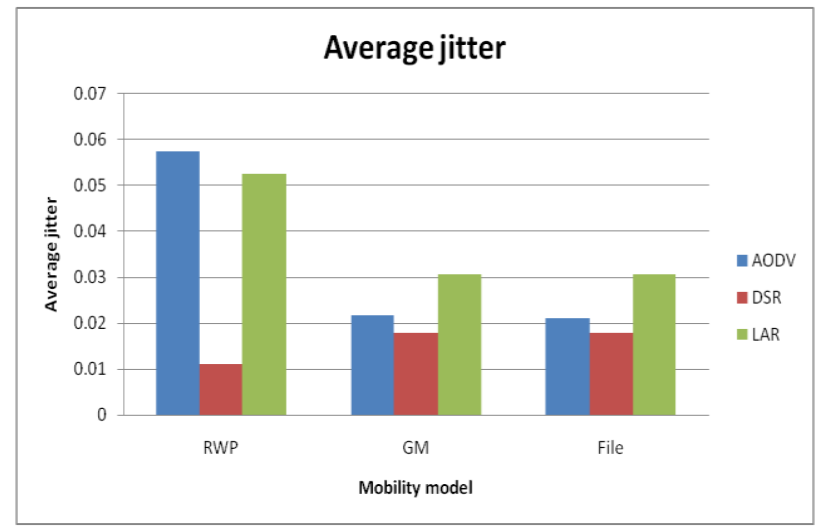

Figure. 7 Average Jitter Vs Mobility Model

Packet Delivery Ratio: Figure. 8 shows the performance of various routing protocols in terms of packet delivery ratio under the effect of mobility. Following inferences can be made:

- The value of packet delivery ratio is highest for DSR among three routing protocols for all the three mobility models (GM, RWP, File).

- AODV has least value of packet delivery ratio among all the three protocols for all the mobility models.

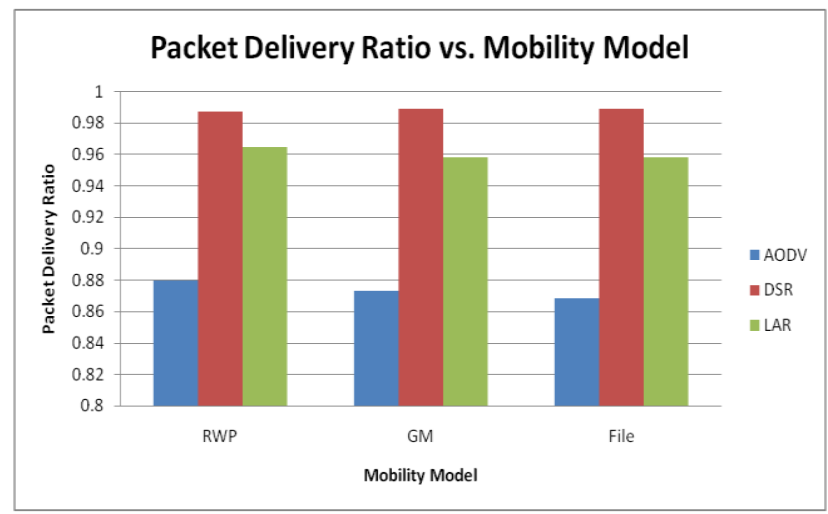

Figure. 8 Packet delivery Ratio Vs Mobility Model

\section{B. Impact on Table Driven Routing protocols}

Average End to End Delay: Figure. 9 shows the performance of various table-driven routing protocols in terms average end to end delay under the effect of mobility. Following inferences can be made:

- The value of average end to end delay is highest for Fisheye routing protocol among all e routing protocols for all the three mobility models.
- The value of average end to end delay is highest for fisheye routing protocol for RWP mobility model followed by group and file mobility models.

- The STAR routing has least value in comparison to other routing protocols for all the three mobility models.

- In case of STAR protocol the file mobility model has the least value of average end to end delay and is in the increasing order for GM and RWP.

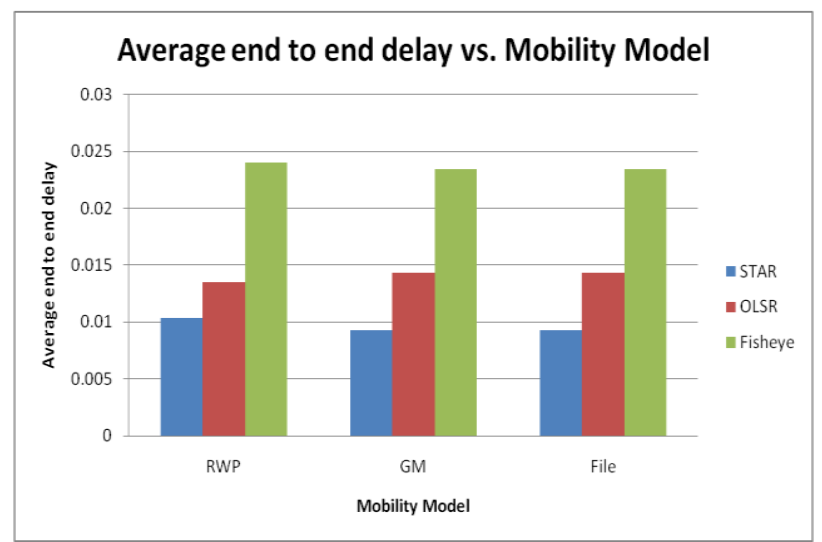

Figure. 9 Average End to End Delay Vs Mobility Model

Throughput: Figure. 10 shows the performance of various table-driven routing protocols in terms of throughput under the effect of mobility. Following inferences can be made:

- The value of throughput is highest for Optimized Link State Routing (OLSR) protocol followed by Fisheye State Routing (FSR) and Source Tree Adaptive Routing (STAR) protocols for all the three mobility models.

- The OLSR routing protocol has highest value of throughput in every mobility model. The values are in decreasing order for RWP, File and Group Mobility.

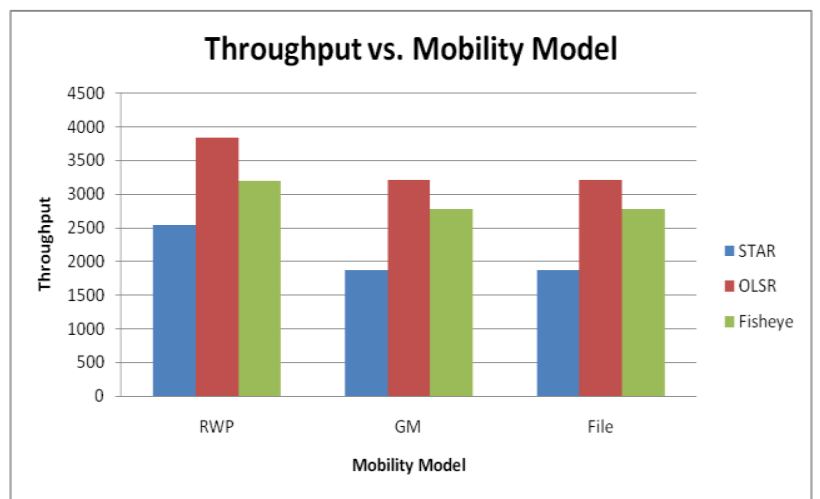

Figure. 10 Throughput Vs Mobility Model

Average Jitter: Figure. 11 shows the performance of various table-driven routing protocols in terms Average jitter under the effect of mobility. Following inferences can be made: 
- The value of Average jitter is highest for FSR routing protocols followed by OLSR and STAR.

- OLSR is having highest value of Average jitter for RWP mobility model followed by File and Group mobility models.

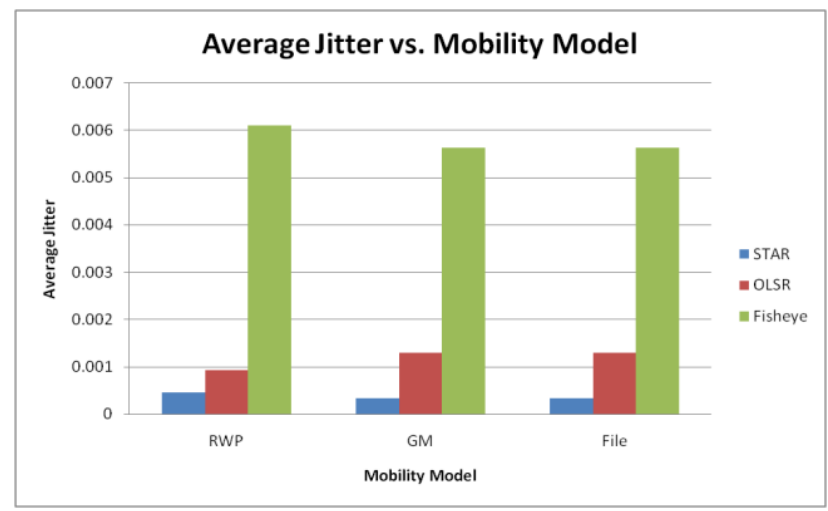

Figure. 11 Average Jitter Vs Mobility Model

Packet Delivery Ratio: Figure. 12 shows the performance of various table-driven routing protocols in terms of Packet Delivery Ratio under the effect of mobility. Following inferences can be made:

- OLSR is having highest value of Packet delivery ratio in comparison to Fisheye and STAR respectively for the RWP mobility model.

- For the group and file mobility the packet delivery ratio is in decreasing order as Fisheye, OLSR and STAR.

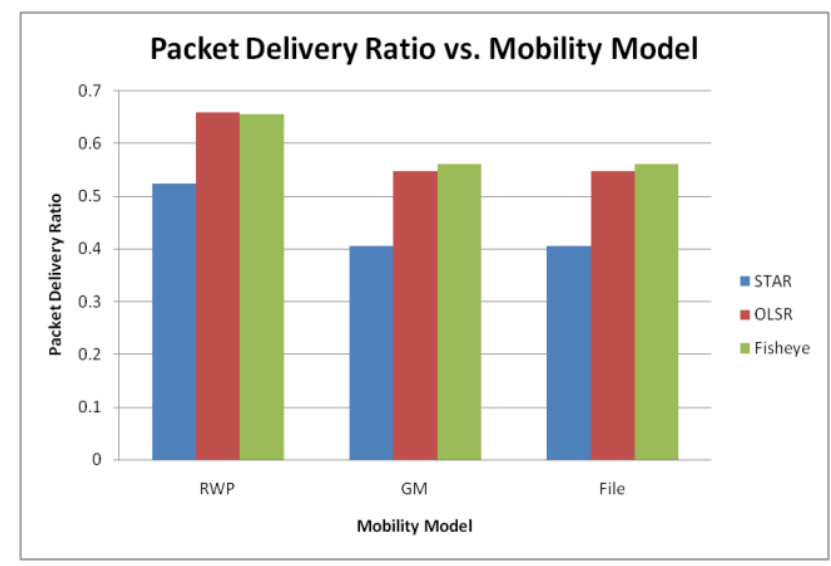

Figure. 12 Packet delivery Ratio Vs Mobility Model

\section{Impact on Hybrid routing protocols}

Average End to End Delay: Figure. 13 shows the performance of various hybrid routing protocols in terms of average end to end delay under the effect of mobility. Following inferences can be made:

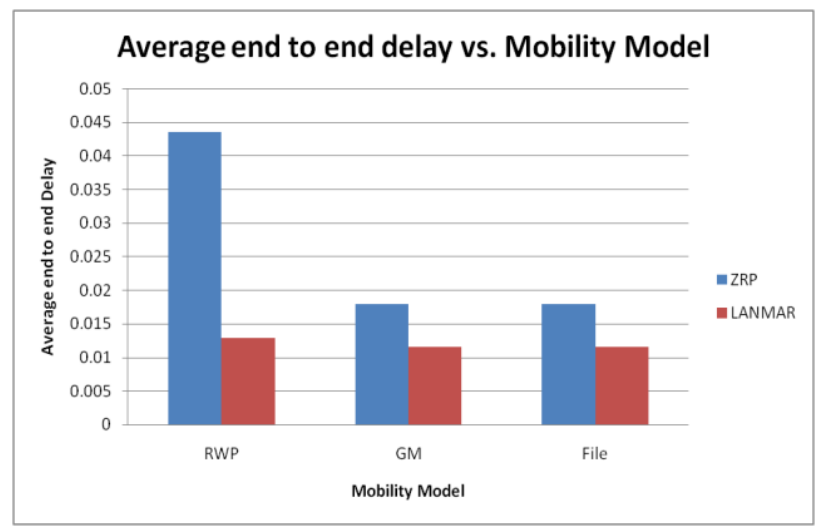

Figure. 13 Average End to End Delay Vs Mobility Model

- Zone Routing Protocol (ZRP) routing protocol is having higher value compared to LandMark routing protocol (LANMAR).

- The value of average end to end delay is highest for RWP mobility model for both the protocols followed by file and group mobility models.

Throughput: Figure.14 shows the performance of various hybrid routing protocols in terms of throughput under the effect of mobility. Following inferences can be made:

- The value of LANMAR is having higher value of throughput compared to ZRP for all the three mobility models.

- For both the protocols the value of throughput is highest for RWP mobility model followed by File and group mobility in decreasing order.

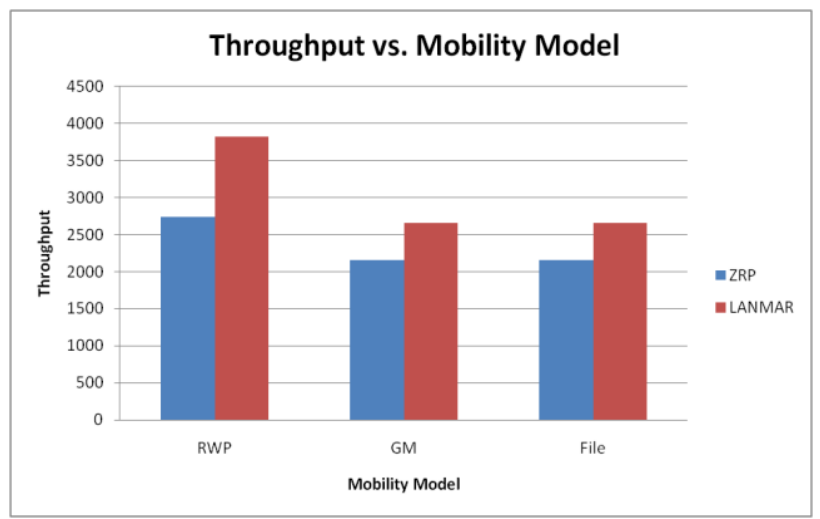

Figure. 14 Throughput Vs Mobility Model

Average Jitter: Figure. 15 shows the performance of various hybrid routing protocols in terms of average jitter under the effect of mobility. Following inferences can be made:

- The value of average jitter is higher for ZRP compared to LANMAR.

- For both the protocols the value of average jitter is highest for RWP followed by Group and file mobility model in decreasing order. 


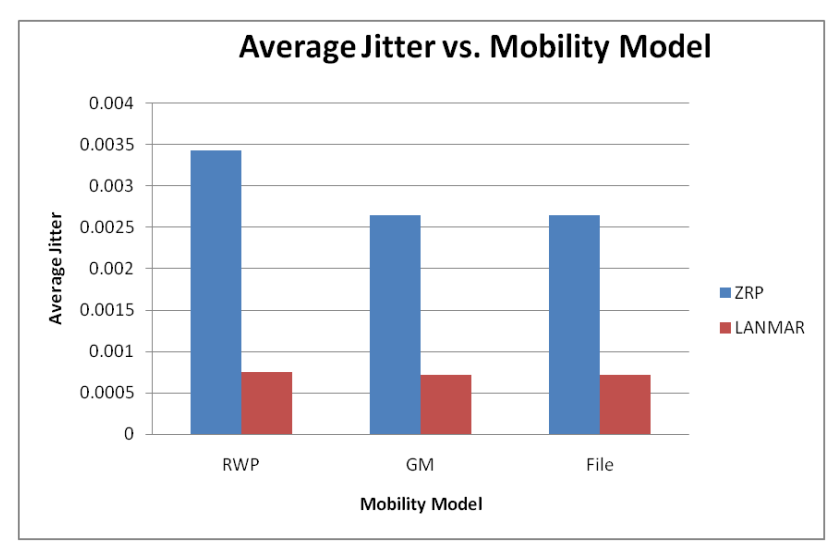

Figure. 15 Average Jitter Vs Mobility Model

Packet Delivery Ratio: Figure. 16 shows the performance of various hybrid routing protocols in terms of Packet Delivery Ratio under the effect of mobility. Following inferences can be made:

- The Value of packet delivery ratio is higher for LANMAR compared to ZRP.

- For both the protocols RWP mobility model is having highest value of packet delivery ratio followed by file and group mobility model in decreasing order.

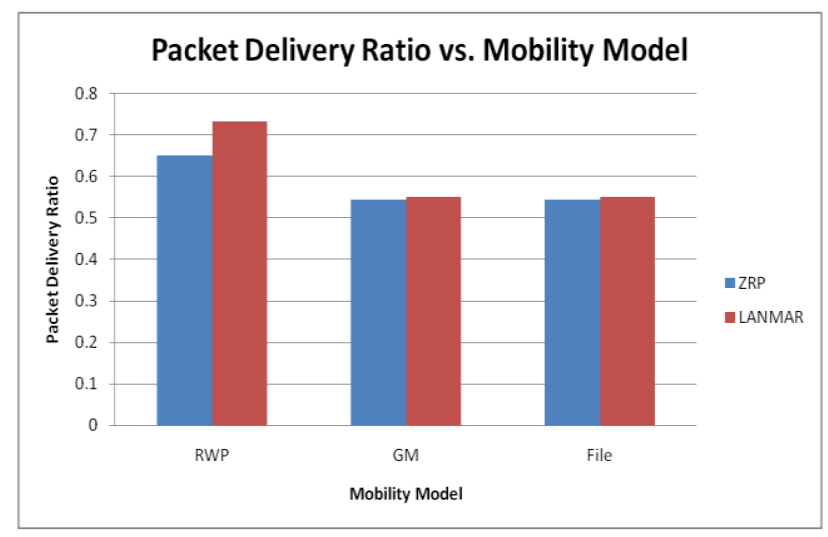

Figure. 16 Packet delivery Ratio Vs Mobility Model

\section{Overall Inference}

Average End-to-End Delay: Figure. 17 shows the performance of various routing protocols in terms of average end to end delay under the effect of mobility. Following inferences can be made:

- The value of average end to end delay is highest for On Demand routing protocol followed by hybrid and Table Driven protocols in case of RWP mobility model.

- The value of average end to end delay is highest for On Demand routing protocol followed by Table Driven and hybrid routing protocols for File and group mobility models.

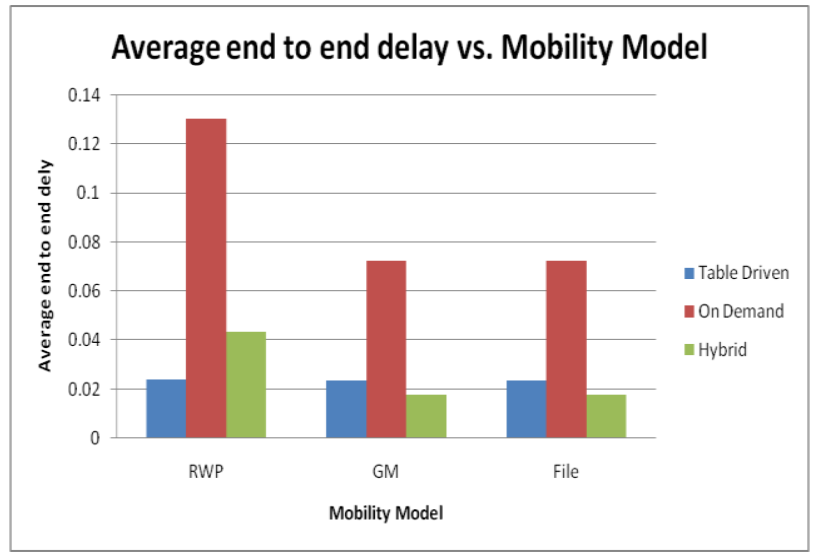

Figure. 17 Average End to End Delay Vs Mobility Model

Throughput: Figure. 18 shows the performance of various routing protocols in terms of throughput under the effect of mobility. Following inferences can be made:

- The value of throughput is having highest value for On Demand routing protocol followed by Table Driven and Hybrid routing protocols for all mobility models.

- The value of throughput is highest for the RWP mobility model followed by File and group mobility models.

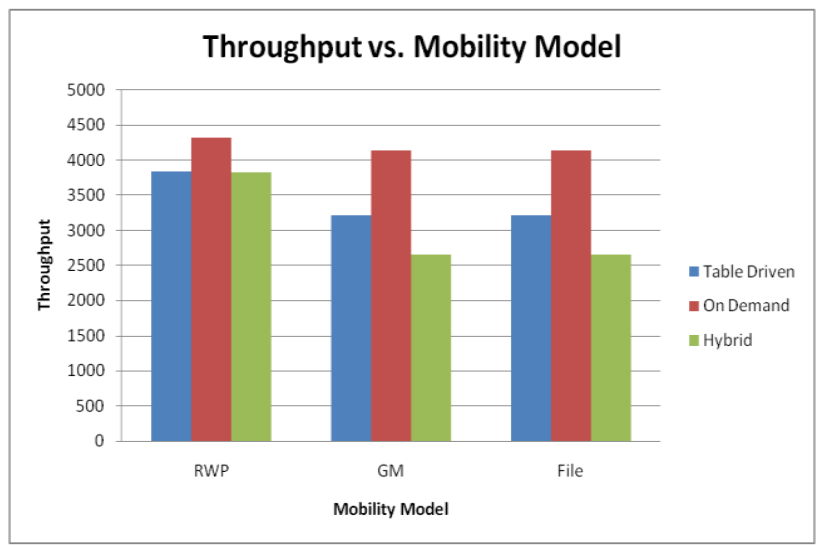

Figure. 18 Throughput Vs Mobility Model

Average Jitter: Figure. 19 shows the performance of various routing protocols in terms of average jitter under the effect of mobility. Following inferences can be made:

- The value of average jitter is highest for On Demand routing protocol followed by Table Driven and hybrid routing protocols.

- The value of average jitter is highest for RWP mobility model followed by File and Group mobility models. 


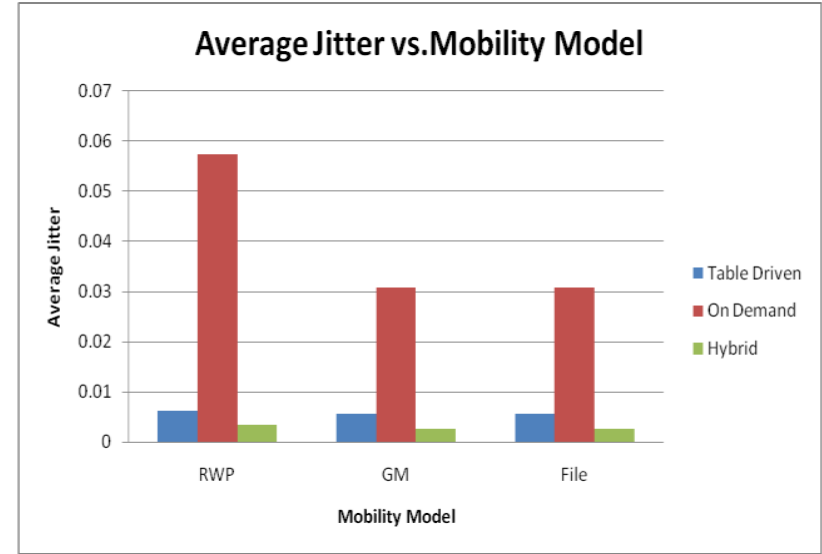

Figure. 19 Average Jitter Vs Mobility Model

Packet Delivery Ratio: Figure. 20 shows the performance of various routing protocols in terms of Packet delivery Ratio under the effect of mobility. Following inferences can be made:

- The value of packet delivery ratio is highest for On Demand routing protocol followed by Hybrid and Table Driven routing protocols in case of RWP mobility model.

- The value of Packet delivery ratio is highest for the group and file mobility for On Demand routing protocols followed by Table Driven and Hybrid routing protocols.

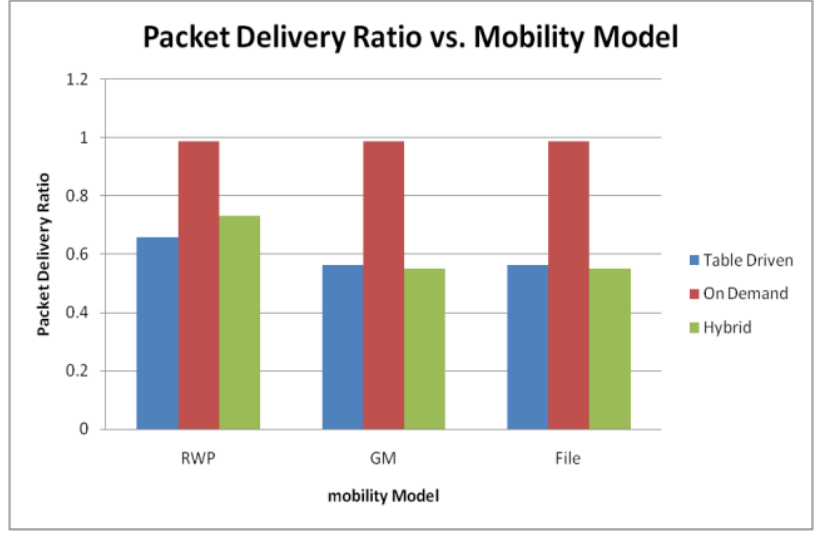

Figure. 20 Packet Delivery Ratio Vs Mobility Model

\section{CONCLUSIONS}

Table II shows the overall comparison of various routing protocols as Table Driven, On Demand and Hybrid routing protocols.

- On Demand routing protocols shows higher value of Average Jitter followed by Table Driven and Hybrid routing protocols.

- The value of average end to end delay is higher for On Demand routing protocol followed by Table Driven and Hybrid routing protocol.

- The value of throughput is higher for On Demand routing protocol followed by Table Driven and Hybrid routing protocol.

- On Demand routing protocols shows highest value of packet delivery ratio followed by Table Driven and Hybrid routing protocols.

- RWP mobility model has highest value of each parameter followed by File and Group mobility.

TABLE II.

AUTHOR(S) OF TEXT/REFERENCE BOOKS

\begin{tabular}{|c|c|c|c|c|c|c|c|c|c|}
\hline \multirow{2}{*}{ Parameter } & \multicolumn{3}{|c|}{ Table Driven routing } & \multicolumn{3}{|c|}{ On Demand routing } & \multicolumn{3}{|c|}{ Hybrid routing } \\
\hline & RWP & File & Group & RWP & File & Group & RWP & File & Group \\
\hline $\begin{array}{l}\text { Average } \\
\text { End to End } \\
\text { Delay }\end{array}$ & Low & Low & Low & High & Medium & Medium & Medium & $\begin{array}{l}\text { Very } \\
\text { Low }\end{array}$ & $\begin{array}{l}\text { Very } \\
\text { Low }\end{array}$ \\
\hline Throughput & Medium & Medium & Medium & High & Medium & Medium & Medium & Low & Low \\
\hline $\begin{array}{l}\text { Average } \\
\text { Jitter }\end{array}$ & Low & Low & Low & High & Medium & Medium & Low & $\begin{array}{l}\text { Very } \\
\text { Low }\end{array}$ & $\begin{array}{l}\text { Very } \\
\text { Low }\end{array}$ \\
\hline $\begin{array}{l}\text { Packet } \\
\text { Delivery } \\
\text { Ratio }\end{array}$ & Medium & Low & Low & $\begin{array}{l}\text { Very } \\
\text { High }\end{array}$ & $\begin{array}{l}\text { Very } \\
\text { High }\end{array}$ & $\begin{array}{l}\text { Very } \\
\text { High }\end{array}$ & High & Low & Low \\
\hline
\end{tabular}

\section{REFERENCES}

[1] J. E. Wieselthier, E. Altman, A. Ephremides, J. P. Macker, H. B. Russell, M. Steenstrup, and S. B. Wicker," Wireless ad hoc networks - part II", IEEE Journal on SAC , Volume 23, Number 3, March 2005.
[2] Hany Samuel,Weihua Zhuang,Bruno Preiss,"DTN Based Dominating Set Routing for MANET in Heterogeneous Wireless Networking", Journal Mobile Networks and Applications Volume 14 Issue 2, April 2009 Pages 154 - 164.

[3] Charles E. Perkins, "Mobile Ad-Hoc Networks," Addison-Wesley(2000). 
[4] Giorgos Papastergiou, Ioannis Psaras , Vassilis Tsaoussidis," Deep-Space Transport protocol: A Novel Transport Scheme for Space DTNs", Computer Communications Volume 32, Issue 16, 15 October 2009, Pages 1757-1767, Elsevier.

[5] J. Mackar and S. Corson, RFC 2501, "Mobile Ad hoc Networking (MANET): Routing protocol Performance Issues and Evaluation Considerations", IETF 1999.

[6] Chim Yuen Chong, Raymond Seah Kwang Wee, Sim Soon Lian, Tan Jia Hui,"Moblie Ad hoc Networking",http://www.dsta.gov.sg/DSTA_horizon s/2006/Chapter_7. Htm.

[7] Laura Marie Feeney. A taxonomy for routing protocols in mobile ad hoc networks. Technical report, Swedish Institute of Computer Science, Sweden, 1999.

[8] http://www.telenor.com/rd/pub/rep03/R_41_2003.pd $\mathrm{f}$

[9] Tracy Camp, Jeff Boleng, Vanessa Davies," A Survey of Mobility Models for Ad Hoc Network Research", Wireless Communication \& Mobile Computing (WCMC): Special issue on Mobile Ad Hoc Networking:Research, Trends and Applications, vol. 2, no. 5, pp. 483-502, 2002.

[10] Bhavyesh Divecha, Ajith Abraham, Crina Grosan and Sugata Sanyal,"Impact of node mobility on MANET routing protocols models" ,Journal of Digital Information Management, Feb 12007.

[11] Nicholas Cooper and Natarajan Meghanathan,"Impact of Mobility Models in MultiPath Routing in Mobile Ad Hoc Networks",International Journal Of Computer Networks \& Communications (IJCNC), Vol. 2, No.1, January 2010.

[12] Santosh Kumar, S C Sharma Bhupendra Suman,"Classification and Evaluation of Mobility Metrics for Mobility Model Movement Patterns in Mobile Ad-Hoc Networks",International journal on applications of graph theory in wireless ad hoc and sensor networks (GRAPH-HOC) Vol.3, No.3, September 2011.

[13] Michael Feeley, Norman Hutchinson, and Suprio Ray,"Realistic Mobility for Mobile Ad Hoc Network Simulation",I. Nikolaidis et al. (Eds.): ADHOCNOW 2004, LNCS 3158, pp. 324-329, 2004.

[14] P. Venkateswaran, Rahul Ghosh, Aritra Das, S.K. Sanyal, R. Nandi,"An Obstacle Based Realistic AdHoc Mobility Model for Social Networks",JOURNAL OF NETWORKS, VOL. 1, NO. 2, JUNE 2006.

[15] Cedric Gael AboueNze, Frederic Guinand and Yoann Pign,"Impact of Obstacles on the Degree of Mobile Ad Hoc Connection Graphs",arXiv:0911.0141v1 [cs.NI] 1 Nov 2009.

[16] Amit Jardosh, Elizabeth M. BeldingRoyer, Kevin C. Almeroth, Subhash Suri,"Towards Realistic Mobility Models For Mobile Ad hoc Networks",MobiCom'03, September 14-19, 2003, San Diego, California, USA
[17] Amit Jardosh, E. M. Belding-Royer, K. C. Almeroth, and S. Suri, "Real world Environment Models for Mobile Ad hoc Networks," IEEE Journal on Special Areas in Communications - Special Issue on Wireless Ad hoc Networks, vol. 23, pp. 622-632, 2005.

[18] Chirag Kumar, C.K. Nagpal, Bharat Bhushan, Shailender Gupta,"Reachability Analysis of Mobility Models under Idealistic and Realistic Environments", published in proceedings by springer, wimoa2012,page no. 519-528.

Mr. Shailender Gupta is B. Tech (Electronics) and M. Tech (Computer Engg.) and pursuing his $\mathrm{Ph}$. D in the area of ad-hoc mobile network security from YMCA University of Science and Technology. His academic interests include network security, automata theory and fuzzy logic.

\section{Shailender Gupta \\ Assistant Professor (Electronics Engg) \\ YMCA University of Science and Technology, \\ Faridabad, India. \\ E-mail: shailender81@gmail.com}

Mr. Chirag Kumar is B. Tech (ECE) from Kurukshetra University and pursuing his M.Tech (ECE) from YMCA University of Science and Technology. His academic interests include network security and fuzzy logic.

Mr. Chirag Kumar

Electronics Engg Department

YMCA University of Science and Technology

Faridabad

E-mail: chiragarora35@gmail.com

Ms. Seema Rani is B. Tech (Electronics \& Communication) from BSAITM and M.Tech (Electronics \& Communication) from YMCA University of Science and Technology. Her academic interests include Mobile Ad-hoc Network, network security and Fuzzy Theory.

\section{Seema Rani}

Assistant Professor(Electronics \& Communication Engg.) BSAITM,Faridabad, India

E-mail: yadav.rani@gmail.com

Mr. Bharat Bhushan is B. Tech (Electronics) from PEC and M.Tech (Electronics) from YMCA University of Science and Technology. His academic interests include Mobile Ad-hoc Network, Network Security.

Bharat Bhushan

Assistant Professor (Electronics Engg.)

YMCA University of Science and Technology,

Faridabad, India.

E-mail: bhrts@yahoomail.com 